\title{
Intra-household decision-making on health and resource allocation in Borgou, Bénin
}

Pierre Ngom

Salome Wawire

Timothee Gandaho

Pierre Klissou

Toussaint Adjimon

See next page for additional authors

Follow this and additional works at: https://knowledgecommons.popcouncil.org/departments_sbsr-rh

Part of the Demography, Population, and Ecology Commons, Family, Life Course, and Society Commons, and the International Public Health Commons How does access to this work benefit you? Let us know!

\section{Recommended Citation}

Ngom, Pierre, Salome Wawire, Timothee Gandaho, Pierre Klissou, Toussaint Adjimon, Mbaye Seye, Emile Akouanou, and Laurie Winter. 2000. "Intra-household decision-making on health and resource allocation in Borgou, Bénin," FRONTIERS Final Report. Nairobi: Population Council. 


\section{Authors}

Pierre Ngom, Salome Wawire, Timothee Gandaho, Pierre Klissou, Toussaint Adjimon, Mbaye Seye, Emile Akouanou, and Laurie Winter 


\title{
Intra-Household Decision-Making On Health And Resource Allocation \\ In Borgou, Bénin
}

\author{
APHRC/Population Council \\ Pierre Ngom \\ Salome Wawire \\ Timothée Gandaho \\ CEFORP \\ Pierre Klissou \\ Toussaint Adjimon \\ PROSAF \\ Mbaye Sèye \\ Emile Akouanou \\ Laurie Winter
}

November 2000

Intra-Household Decision-Making On Health And Resource Allocation In Borgou, Bénin. This study was funded by the UNITED STATES AGENCY FOR INTERNATIONAL DEVELOPMENT (USAID) under the terms of Cooperative Agreement number HRN-A-00-98-00012-00 (FRONTIERS). The opinions expressed herein are those of the authors and do not necessarily reflect the views of USAID. 



\section{SUMMARY}

Bénin, as with many other West African countries, is characterized by high fertility and mortality levels, despite governmental efforts, backed up by the international donor community, to improve the overall health and well being of its population. To crystallize these efforts, the Government of Bénin initiated health sector reforms in 1994. To support this government initiative, USAID has funded the Integrated Family Health Project (PROSAF), which is working with the Departmental Directorate of Health and other partners in Borgou Department, which has the worst health and reproductive health indicators in the country. The African Population and Health Research Centre (APHRC) carried out this study, with support from FRONTIERS and USAID, in order to inform PROSAF about sociocultural factors that can impede health improvements in Borgou. More specifically, the study aims to identify key players in household decision-making processes, map out patterns of health seeking behaviour, elucidate how such patterns are associated with prevailing health services utilization, assess community valuation of existing health services and products, and recommend to PROSAF approaches to identified target groups of their intervention.

The findings indicate that for all the communities under study, health care is not considered a priority in the allocation of household resources. Resource prioritisation at the household level is generally made without involving women. Choice and timing of treatment of illness is based on availability and quality of health services, perceived cure for specific illnesses, the severity of the illness and the cost of health services. Modern medical care is sought only when an illness persists and other sources of health care, for example traditional treatment and self-medication, have been exhausted.

The quality of health care is by far the greatest concern for community members when evaluating health services and products. This includes lack of drugs and technical facilities like laboratories, lack of qualified medical personnel, absenteeism by hospital staff and poor provider/patient relationships. If they could afford it, pregnant women would have preferred to deliver in private hospitals where they are better received and treated. Distance to health facilities is insignificant to the communities, provided quality health care is guaranteed.

Knowledge of family planning is high in most areas. However, use of modern family planning methods is low, owing to perceived and/or real health side effects of the pill and the injection. Besides, the existing services are not friendly to the youth. Adolescent boys and girls expressed their preference for family planning outlets set up outside the health facility in order for the youth to avoid being chased away and insulted by health facility staff.

A dissemination seminar was held in November 2000 in Bénin to share the study results with representatives of the Ministry of Health, NGOs working in Borgou, PROSAF, and USAID. The participants discussed the implications of the results on existing programmes and made recommendations on how the results could be used to improve their performance. 



\section{CONTENTS}

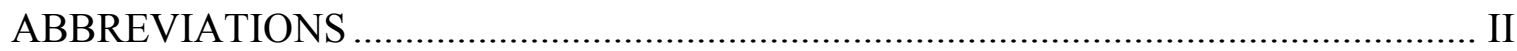

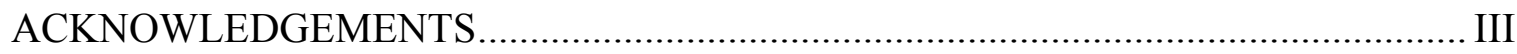

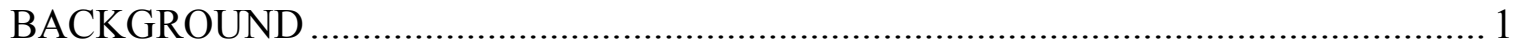

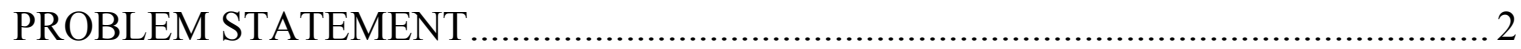

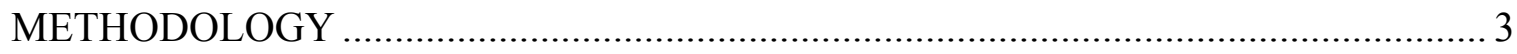

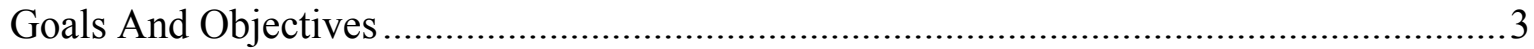

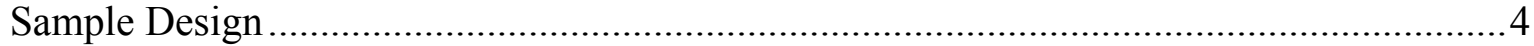

INTRA-HOUSEHOLD RESOURCE ALLOCATION_................................................ 5

Resource Generation At The Household Level .................................................................5

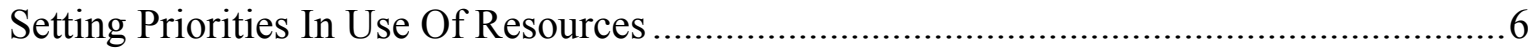

Resource Allocation And Health Care Expenditures ...........................................................

ILLNESS PATTERNS, AETIOLOGY, AND HEALTH SEEKING BEHAVIOR............. 8

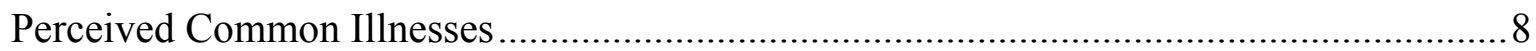

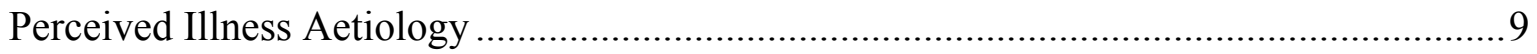

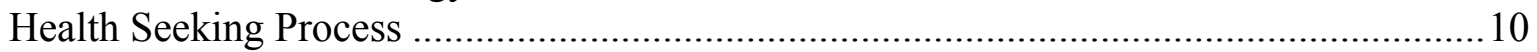

Pattern Of Health Seeking Behaviour...........................................................................

Factors Influencing Health Seeking Behaviour............................................................... 11

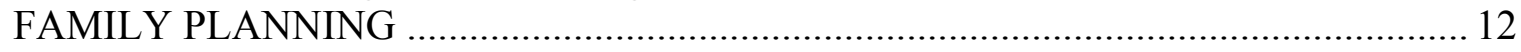

Knowledge Of Family Planning In The Community ………...........................................12

Perceptions About Use Of Contraceptive Methods............................................................ 14

Contraceptive Use Among The Youth .............................................................................. 16

COMMUNITY VALUATION OF HEALTH SERVICES AND PRODUCTS ............... 19

Access And Cost Of Health Services And Products ..........................................................19

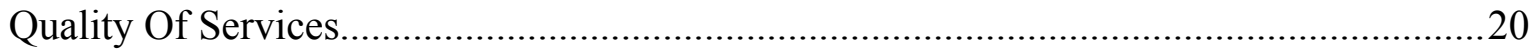

Suggestions For Improvement By Community Members ..............................................21

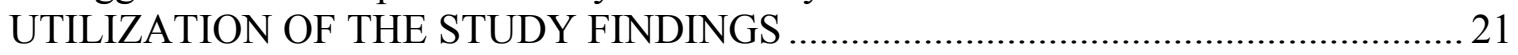

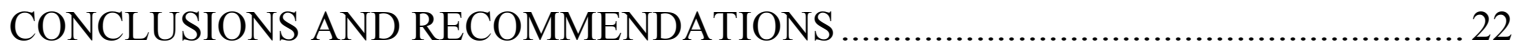

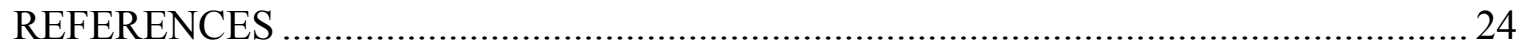




\begin{tabular}{ll} 
ABBREVIATIONS \\
PROSAF & Projet Intégré en Santé Familiale (Integrated Family Health Project) \\
CEFORP & $\begin{array}{l}\text { Centre de Formation et de Recherche en Population (Population Research and } \\
\text { Training Centre) }\end{array}$ \\
APHRC & African Population and Health Research Centre \\
TFR & Total Fertility Rate \\
BDHS & Bénin Demographic and Health Survey \\
USAID & United States Agency for International Development \\
IDIs & In-depth Interviews \\
FGDs & Focus Group Discussions \\
STDs & Sexually Transmitted Diseases \\
IUD & Intra-Uterine Device \\
HIV & Human Immunodeficiency Virus \\
AIDS & Acquired Immunodeficiency Syndrome \\
CFA & Communauté Financière d'Afrique \\
NGOs & Non-Governmental Organisations \\
BCC & Behavior Change Communication \\
DDH & Departmental Directorate of Health \\
IEC & Information, Education and Communication \\
EDUCOM & Education Communautaire \\
\hline
\end{tabular}




\section{ACKNOWLEDGEMENTS}

This study results from fruitful collaboration between Projet Intégré en Santé Familiale (PROSAF), the Ministry of Health of Benin, Centre de Formation et de Recherché en Population (CEFORP), and the Population Council through the African Population and Health Research Centre (APHRC) and Frontiers in Reproductive Health (FRONTIERS), with financial support from USAID/Bénin.

We wish to thank all the above institutions, as well as the administrative and health officials of Borgou, especially the District Medical Officers, the District Chief Executive, and the Departmental Director of Health.

We are grateful to all those who contributed in some way to the success of this study. Special thanks go to the populations of the study sites (Banikoara, Bembereke, Kalale, Kandi, and Malanville), and fieldworkers and field supervisors. 



\section{BACKGROUND}

Bénin covers an area of 114,763 square kilometres on the West African coast. It borders Burkina Faso and Niger to the north, Nigeria to the east, Togo to the west, and the Atlantic Ocean to the south. According to the 1999 African Development Report of the African Development Bank, Bénin's Gross National Product was 380 US dollars per capita ( République du Bénin, 1999a). Life expectancy at birth was 56 years, and one third of the population live under the poverty line.

The national population census of February 1992 put the population of Bénin at 4,915,555 inhabitants. About 48 percent of the total population is below the age of 15 years (République du Bénin, 1995). This young age structure is sustained by a high annual population growth rate of 3.2 percent and a total fertility rate (TFR) of 6 children per woman of reproductive age over the past decade (République du Bénin, 1997).

Although health indicators have substantially improved since the country's independence, they are still poor. The 1996 Bénin Demographic and Health Survey (BDHS) indicates that the infant mortality rate fell from $136 / 1000$ in $1971 / 76$ to $94 / 1000$ in $1991 / 96$, a mortality level that is similar to that of Burkina Faso. Maternal mortality is still unacceptably high, 498 maternal deaths per 100,000 live births (République du Bénin, 1997).

These poor health indicators are a matter of concern, given the fact that, since 1989, Bénin has had a national health policy which was inspired from recommendations that emerged from the 1978 Alma Ata and 1987 Bamako Initiative conferences (République du Bénin, 1999b). After evaluating its national health policy in 1994, the Government of Bénin initiated health sector reforms, which focussed on improving the quality of health care, the management of resources (human, financial, logistics), and the coverage of health services through an integrated approach. The Projet Intégré de Santé Familiale (PROSAF, Integrated Family Health Project) has the mandate to support current government's efforts to achieve these health goals (Programme Intégré de Santé Familiale dans le Borgou, 1999).

PROSAF covers the Département of Borgou, one of the seven administrative zones of Bénin. Borgou has a population of 827,925 inhabitants and covers an area of 51,745 square kilometres in the northeastern parts of the country. Only 16 percent of the Borgou population live in urban areas, compared to 34 percent at the national level. Unlike other parts of Bénin, Borgou is mainly Muslim (60 percent of its population). Women marry early - on average at age 19 years - and one out of two married women live in polygamous unions. While enrolment rates in Bénin are 52 percent for boys aged 6-15 years and 34 percent for girls in the same age groups, the corresponding figures are 31 percent for boys and 21 percent for girls in Borgou (République du Bénin, 1994; 1999c).

Borgou is thought to have the worst health and reproductive health indicators in Bénin . The 1996 Bénin Demographic and Health Survey (BDHS) reveals that Borgou has the highest total fertility rate, 7.4 children per woman ( 8.1 in rural Borgou) compared to 6.3 at the national level. Modern family planning methods are seldom known and used by Borgou women, 44.8 percent and 2.5 percent respectively, whilst in Bénin as a whole the corresponding figures are 79.8 percent and 3.4 percent. However, total unmet need for family 
planning was estimated by the 1996 BDHS at 26.7 percent in Borgou and 20.6 for Bénin . In-depth analyses from the BDHS show that, in Borgou, the infant mortality rate for the 1991-96 period is the second highest in the country, and vaccination coverage is at its lowest levels (41 percent). The highest percentage of women of reproductive ages with chronic malnutrition is also found in Borgou, 18 percent according to the BDHS (République du Bénin , 1994; 1999c).

\section{PROBLEM STATEMENT}

Low utilization of health services, as observed in Borgou and many other similar rural African settings, depends not only on accessibility factors (e.g. physical proximity, cost, etc) but also on local patterns of health seeking behaviour, defined as a constellation of activities and beliefs exhibited by individuals and their social circle in response to bodily indications perceived as symptoms (Mechanic, 1978). These activities include prevention and identification of symptoms and seeking respite from the symptoms exhibited (Kasl and Cobb, 1966; Ware et al 1992).

Recognition of symptoms or indicators of illness is essential to the initiation of health seeking and treatment. Whether or not particular bodily changes will be identified as symptoms is a function of local cultural definitions of disease. An awareness of cultural variability in symptom definition also helps to illuminate the pattern of illness neglect that has been identified in various communities in Africa. For example, among the Dogon people of Mali, schistosomiasis is left untreated in more than 50 percent of the cases because it is so common that it is considered normal (Coppo et al 1992). Among the Yoruba in Nigeria, mothers' belief in Abiku (special children who have come from the spirit world and can die at will unless special rituals are performed) influences their identification of some symptoms as possible indicators of illness in some children, which would be considered normal in other (abiku) children (Feyisetan et al, 1997). However, a study by Sauerborn et al (1996) in Burkina Faso suggests that some cases of negligence of illness treatment stem from fatalistic attitudes of society towards illness among selected members of the society, such as children and the elderly.

Several authors have emphasized the need to consider the cultural beliefs and practices of communities when designing measures and programs aimed at improving their health. There is need for health planners to understand local meanings of illness and behavioural responses to illness because these are basic factors influencing community reactions to public health programmes (Feyisetan and Adeokun, 1992; Suchman, 1983; Feyisetan 1988, Feyisetan et al 1997). Feyisetan and Adeokun (1992) argue that non-adoption of modern curative and preventive measures cannot be attributed to poverty alone since the costs of some curative and preventive measures are affordable in many African societies. Rather, they suggest that the gap between awareness and availability of modern health measures and health seeking behaviour must be sought in the cultural and social determinants of behaviour in the quest for health care.

Patterns of health seeking behaviour are very often context specific and require an in-depth qualitative investigation of key questions; for instance, when a child is sick, does the mother 
have a say regarding where to seek health care? Who is the key household decision-maker when it comes to resource allocation in general and health care expenditures in particular? Addressing these questions can help unveil socio-cultural factors that underlie low utilization of modern health services. In Borgou, we do not know much about how decisions regarding health care are made within households. Even less is known about gender roles in such household decision-making processes. Understanding socio-cultural factors that may impede improvement in health conditions in Borgou is crucial to PROSAF's activities in Borgou.

\section{METHODOLOGY}

\section{Goals And Objectives}

This study provides information to PROSAF, the Departmental Directorate of Health and USAID on household decision-making in the area of health care and resource allocation in Borgou. It is expected that this will guide the design and implementation of a pilot family health project.

The study has the following immediate objectives:

- To map out intra-household decision-making dynamics regarding health and resource allocation processes at the household level.

- To identify current patterns of health seeking behaviour and their relationship with the use of health services in Borgou.

- To assess community valuation of the existing health services in Borgou.

- To recommend approaches for reaching specified target groups with family health services.

Three major hypotheses underlie the above research objectives:

a) Intra-household decision-making: In most African societies, decisions regarding health care at the household level are highly dependent on the balance of power between household members. When designing participatory approaches to health service delivery, it is important to identify the key decision-makers regarding households' production of health. It is also crucial to put health care decisions within the broader context of intra-household decision dynamics guiding other factors that have a direct or indirect bearing on health seeking behaviour such as health care costs and how resources are mobilized to cover these costs, and women's autonomy regarding household-level decisions.

b) Community valuation of health services and products: Poor access and low quality of care may seriously impede the proper patronage of existing health services. Individual valuation of health services and products may be influenced by communities' own prioritisation of their various needs. It is hypothesized for example, that health needs may not rank higher than other household's needs such as food.

c) Patterns of health seeking behaviour: Intra-household decision dynamics in the area of health care and resource allocation and community valuation of health services and products 
constitute two important determinants of local patterns of health seeking behaviour. Household-level illness diagnosis is associated with the choice made between health treatment alternatives (home-made, traditional healer, modern health services, products in open market). Both illness diagnosis and choice of treatment are in turn influenced by beliefs regarding causal mechanisms for the prevailing diseases.

The resulting patterns of health seeking behaviour determine ultimately the net burden of disease in a given society.

\section{Sample Design}

The study used qualitative methods to collect the data required to address the objectives listed above. Fieldwork methods relied mainly on in-depth interviews (IDIs) and focus group discussions (FGDs) with individuals and couples in communities, and with service providers (Table 1). The study sample comprised of communities representing the whole Département of Borgou. FGD and IDI participants were stratified by the five out of eight major ethnic groups of Borgou (Bariba, Peulh, Dendi, Yoruba, and Yoa Lokpa), by age (youth: 15-24 years, adults: 25-49 years, elderly: 50 years or more), and by gender (men, women).

Selection of districts to host the FGDs and IDIs was based on the relative representation of each of the major ethnic groups mentioned above. The district with the highest percentage of a given ethnic group was selected as the area where fieldwork will be carried out to collect information on that ethnic group. It must be noted that although a higher concentration of Peulh is found in Kalale district (68 percent), Bembereke district was sampled to satisfy PROSAF's wish to have two of its existing three pilot districts included in the study. The other PROSAF pilot area in this study is Banikoara district. To take into account the views of service providers in each of the five districts, IDIs were carried out with the District Medical Officer, one Nurse, one Midwife, one Traditional Healer, and one Community Agent. 
Table 1: Number of In-depth Interviews (IDI), and number of focus groups discussions (FGD) by district and respondents' ethnicity, age and gender

\begin{tabular}{|c|c|c|c|c|c|c|c|c|c|c|}
\hline \multirow{2}{*}{$\begin{array}{l}\text { District } \\
\text { (Ethnic } \\
\text { group) }\end{array}$} & \multirow[b]{2}{*}{ Age } & \multirow[b]{2}{*}{$15-24$} & \multicolumn{2}{|c|}{ Males } & \multirow[b]{2}{*}{ ALL } & \multirow[b]{2}{*}{$15-24$} & \multicolumn{2}{|c|}{ Females } & \multirow[b]{2}{*}{ ALL } & \multirow[b]{2}{*}{ Total } \\
\hline & & & $25-49$ & $50+$ & & & $25-49$ & $50+$ & & \\
\hline \multirow{2}{*}{$\begin{array}{l}\text { Banikoara } \\
\text { (Bariba) }\end{array}$} & IDI & 3 & 8 & 2 & 13 & 3 & 3 & 3 & 9 & 22 \\
\hline & FGD & 2 & 1 & 1 & 4 & 1 & 1 & 1 & 3 & 7 \\
\hline \multirow{2}{*}{$\begin{array}{l}\text { Bembereke } \\
\text { (Peulh) }\end{array}$} & IDI & 2 & 7 & 2 & 11 & 2 & 4 & 3 & 9 & 20 \\
\hline & FGD & 1 & 2 & 1 & 4 & 1 & 1 & 1 & 3 & 7 \\
\hline \multirow{2}{*}{$\begin{array}{l}\text { Kalale } \\
\text { (Boo) }\end{array}$} & IDI & 2 & 4 & 5 & 11 & 2 & 5 & 3 & 10 & 21 \\
\hline & FGD & 1 & 1 & 2 & 4 & 1 & 1 & 1 & 3 & 7 \\
\hline \multirow{2}{*}{$\begin{array}{l}\text { Kandi } \\
\text { (Yoruba) }\end{array}$} & IDI & 1 & 8 & 3 & 12 & 3 & 5 & 4 & 12 & 24 \\
\hline & FGD & 1 & 1 & 1 & 3 & 1 & 2 & 2 & 5 & 8 \\
\hline \multirow{2}{*}{$\begin{array}{l}\text { Malanville } \\
\text { (Dendi) }\end{array}$} & IDI & 3 & 6 & 3 & 12 & 3 & 4 & 2 & 9 & 21 \\
\hline & FGD & 1 & 1 & 1 & 3 & 2 & 1 & 1 & 4 & 7 \\
\hline
\end{tabular}

\section{PRINCIPAL FINDINGS}

\section{INTRA-HOUSEHOLD RESOURCE ALLOCATION}

Household members have priorities when allocating available resources to their needs, including health care. To map out intra-household decision-making regarding health care, it is important to examine how resources are generated and pooled at the household level, and how spending priorities are set. This will indicate whether health care is among the top priorities considered in resource allocation. Such information is crucial because it helps one to better understand the resulting patterns of health seeking behaviour.

\section{Resource Generation At The Household Level}

Agriculture is the main economic activity of the populations targeted in the present study. Trading was the second most important livelihood activity. This emerges clearly from the focus group discussion sessions and in-depth interviews, with some variations from one site to another. 
The Boo of Kalale, Dendi of Malanville and the Bariba of Banikoara depend on crop production for their livelihood. The cash crops grown include cotton, groundnuts, cashew nuts and onions (mainly in Malanville), while grains like rice, millet and sorghum are grown for subsistence. The younger boys engage in carpentry and masonry, while the girls do tailoring and sell foodstuff for a livelihood. Although cotton production was considered to be very lucrative, the general feeling from the interviewees is that its profitability is on the decline, and this situation is worsened by the fact that, according to the elderly, children are no longer willing to help in the farms.

"Nowadays, it is cashew nuts [which are more lucrative], but before it was cotton." (Boo, married man, 60 years, Kalale)

"We grow cotton, but nowadays children no longer help parents in the farms." (Boo, married man, 59 years, Kalale)

The Peulh and the Yoruba, though they engage in agriculture, depart from this general trend in that they have economic activities that are specific to them. As shown in the analyses that follow, the Peulh and the Yoruba assign substantial importance to cattle rearing and trading activities respectively.

"Apart from our cows, we don't have any other source of revenue. A Peulh without cows is a lost Peulh." (Peulh, married man, 54 years, Bouanri, Bembereke)

"What I do, it is business, and this occupies me all the time. I buy things and sell them. It is from this trading that we eat and drink. When my supplies are all sold, I go back to Cotonou to buy things again... During the rainy season, I have my children who come for holidays from school. Instead of letting them run around, I arrange for a small plot where they farm maize, groundnuts and millet. We use this for our food." (Married man, 48 years, Kandi)

How the study population uses the revenue generated from these activities is closely associated with local patterns of health seeking behaviour. In turn, pooling of resources at the household level for health care depends on how households prioritise their expenses.

\section{Setting Priorities In Use Of Resources}

Intra-household allocation of resources was investigated in the study by inquiring about the priority areas the FGD participants usually spend their financial earnings on, and how the decision is made at the household level. One finding that cuts across all FGD discussions in all five study sites is that, when there are major in-flows of substantial revenues in the household, members meet and deliberate on decisions to be made on the priority expenditures.

"There are consultations at the household level to decide what to do." (Boo, married man 29 years) 
Such consultations generally take the form of a meeting between the household head, generally an adult or elderly male, and his adult sons. Other household members are only considered for consultation if they are major contributors to the household income.

\section{Resource Allocation And Health Care Expenditures}

When asked about the outcome of consultative meetings on household expenditure, FGD participants indicated that the priority is always on a few key areas which include building new housing units, buying farming equipment and livestock, organizing marriages, funerals and naming ceremonies. There was an outcry against the current tendency to spend too many resources on such ceremonies, especially for funerals.

"For us, the Bariba, what is most important is to get your plot and build in it. The rest of the money we use it ourselves." (Bariba, married man, 30 years, Banikoara)

"In our community here, what swallows our money is the ceremonies. It is the ceremonies that make us broke.” (Bariba, married man, 49 years, Banikoara)

There are however two major deviations which merit further examination, that is the importance of schooling expenditure among the Yoruba and expenditure on religious activities among the Dendi. For the Yoruba, the priority expenses are paying for school fees, and financing marriages, naming ceremonies and funerals. The Dendi accord importance to their religious beliefs to the extent that they reserve some household income for religious activities. The majority of them are Muslim and they spend a substantial amount of money on Islamic pilgrimages to Mecca.

"Funerals, marriages and outdoor activities are of course important events for which we spend a lot of money. However, the most important of our expenses is related to the schooling of our children in order to guarantee them a better future." (Yoruba, married man, 40 years, Kandi)

"The priority is to buy oxen, carts and water pumps." (Dendi, unmarried adolescent girl, 20 years, Malanville)

"They go to Mecca for the pilgrimage." (Dendi, married woman, 50 years, Malanville)

When setting priorities for household expenditure, participants in both FGDs and IDIs did not even mention women as possible partners in the decision-making process. The interviewers had to prompt them by asking such questions as "If a woman has her own money, should someone tell her what to do with it?" The responses given clearly indicate that women in all the five study areas are generally not included in the process of decisionmaking concerning household resource allocation and expenditure. The husband and/or eldest son, in consultation with other household members, make the decisions without consulting the women in the household. 
"It is the husband who should decide on how the money should be used. If you have a wife, even if she has money, the money is yours." (Peulh, married man, 62 years, Bembereke)

"My money and myself, we are under my husband's control." (Boo, married woman, 48 years, Kalale)

The exclusion of women when allocating resources at the household level originates from normative gender roles in the household. When asked what society expects from women, most interviewees were of the view that women had to be submissive to the husband and inlaws, respectful towards visitors and neighbours and hardworking especially at household chores such as cleaning and cooking. On the contrary, men were to be hardworking in order to be able to take care of their wives, children and parents in terms of feeding, health care and shelter. This situation is reinforced by the patriarchal nature of the societies under study, giving all the seemingly important responsibilities to the husband and his relatives, irrespective of the source of household income.

"The rule is that women can not do anything without alerting the husband, women who do not follow this are not many in this community." (Bariba, married man, 49 years, Banikoara)

Health care expenditures are obviously not a priority for the study populations. What seem to be given a prominent role when strategizing for resource allocation are key components of household production and reproduction functions. This reflects rational calculations at the household level given the agrarian nature of the local economy and the high fertility of the study populations.

The above results point to the fact that health care costs are not met through a process of generalized household-level pooling of resources, such as the one that underlies investments in housing and agriculture. To cover health care costs, household members will therefore depend largely on non-pooled resources that are available at the time of occurrence of a given illness episode. This implies that decisions about the timing and type of treatment will depend on who is controlling those non-pooled resources when they are needed. In turn, household members who control resources for health care will make decisions regarding timing and type of treatment based on norms and beliefs about illness diagnosis and illness aetiology. The resulting patterns of health-seeking behaviour are described in the next section.

\section{ILLNESS PATTERNS, AETIOLOGY, AND HEALTH SEEKING BEHAVIOR}

\section{Perceived Common Illnesses}

FGD participants were asked to mention the most common illnesses in their respective communities. Diarrhoea and vomiting (often mentioned together) were considered as the main causes of death for all ages in all the study sites. However, it is worth noting that 
diarrhoea and vomiting are vital symptoms of cholera and therefore the disease being experienced may, in fact, be cholera.

It is also apparent that the most common and feared diseases are infectious, which explains their enormity and fatality among the study populations. Among pregnant women, bleeding, pain in the lower abdomen (commonly referred to as stomach ache), pain in the lower back (commonly referred to as waist pain), vaginal itching and morning sickness (vomiting and dizziness) are the common problems across the study areas. For children, the respondents mentioned meningitis, measles, vomiting and diarrhoea and fever (probably malaria) as common illnesses in all the study sites.

\section{Perceived Illness Aetiology}

Vomiting and diarrhoea are the most common and fatal conditions that affect people of all ages across all the study sites. The respondents were asked what they perceived as the cause of the disease and their responses dwelt within the precincts of hygiene. Vomiting and diarrhoea are believed to originate from lack of clean drinking water, forcing both humans and cattle to drink the dirty water that is available. However, among the Boo of Kalale, witchcraft was identified as a serious cause of illness in their community.

"Men over here do not have clean water to drink. It is the water that makes us sick. Even our cattle too, do not have water to drink. So we are all sick." (Peulh, married man, 42years, Bembereke)

"I would like to talk about mouth sores. This kills a lot of children. Very often, people say that it is due to witchcraft." (Boo, married man, 52 years, Kalale)

With respect to ill health among pregnant women, prolonged labour and other delivery complications are perceived to occur due to lack of blood in the body, or a result of noncompliance in the observance of food taboos during pregnancy. For children, the main diseases are malaria and diarrhoea. The perceived cause of malaria is mosquito bites, while diarrhoea and fever among children is associated with teething.

Apart from maternal and child health issues, respondents were also asked to express their views on the causes of sexually transmitted diseases (STDs) prevailing in their respective communities. It was surprising that respondents in Bembereke and Banikoara associated STDs with hot weather conditions or eating too many mangoes.

"... When it is hot, we have difficulties urinating. Even if we take medicines, it does not stop. You can squat for two minutes without being able to urinate!" (Peulh, married woman, 23 years, Bembereke)

"When the weather is very hot, that causes gonorrhoea. When you eat plenty of mangoes you can also get gonorrhoea." (Bariba, unmarried adolescent, 21yrs, Banikoara) 


\section{Health Seeking Process}

At the household level, the process of seeking modern health care was found to vary considerably between the adult men on one hand, and other household members on the other. While adult men who fall sick can independently decide to seek health care, women, children, adolescents, and the old consistently indicated that it is another household member who usually determines the timing and the type of treatment when they are subject to illness episodes.

"I was the one who decided because I was the one who was sick." (Boo, married man, 30 years, Kalale)

"Yes, they [women] come at night..... Women wait for their husbands to come back home from their daily activities. So it is in the night that they come, when their husbands are back, that is when they bring their children for consultations. I have noted that there are more consultations during the night as compared to the daytime." (Service provider, 48 years, Malanville)

"Because we are together.... For us who are peasants, if you are married, it is your husband who takes care of you." (Boo, married woman, 30 years, Kalale)

For women of reproductive age and their children, it appears clearly from the in-depth interviews in all the five study sites that it is the husband/father who decides on when and where to go for health care. To explain this, respondents unanimously agreed that it was the responsibility of husbands/fathers to take care of the health of the women and children. Adult men were of the view that deciding over their wives' health was justified because the husbands brought the women into the household. They held a similar argument for children whom they considered their property.

The main underlying reasons for the above decision-making process is that adult men are responsible for the health care costs for women and children. The study found that even in situations where the wife pays for her own health care, the husband must reimburse the money spent to her afterwards. This has considerable implications for the timing and type of treatment to be sought. Depending on whether or not he is willing and/or able to pay for medical attention, the husband/father of a sick woman/child may decide to delay modern treatment and rely on cheaper traditional medicines for a while. Depending on their own assessment, adult males may also judge the illness of a woman/child as not serious enough to merit medical attention.

"It is my father who..... He brought the traditional medicine thinking that I will improve so that he can dodge the health centre. Since I was not getting any better, my mother decided to take me to the health centre." (Bariba, adolescent girl, 19 years, Banikoara). 


\section{Pattern Of Health Seeking Behaviour}

When community members get sick, they do not usually seek health care from modern health facilities immediately. Instead, they opt for other alternatives, including not seeking medical care at all, self-medication with drugs obtained from drug vendors, back street marketers, over the counter in shops and pharmacies, and traditional medicine.

"What we did? I relied on...we used traditional medicine and fresh milk. That is what we did first, for three days. When she did not improve, I went to see a medical doctor. He came to the house and gave her some injections; he also sold us some medicine. Even that did not work. Then I asked her to go to Bembereke where she also got some medicines but still with no effect. We tried again 'black' medicine, she drank it and bathed with it and she started getting better. So we did not use just one type of medicine for her to recover her full health." (Yoruba, married man, 48yrs, Kandi)

\section{Factors Influencing Health Seeking Behaviour}

Availability And Quality Of Health Services: Most modern health facilities are situated far from many residents, requiring extra expenditure in terms of transport and time. Shortage of medicines in health facilities leads people to rely on alternative sources of health care. Sometimes patients who start treatment in modern health facilities drop out along the way because they feel that the quality of services offered are not sufficient for full recovery.

"Even if you prescribe Gentamicine, Diazepan injections, HDV injections, serums... we are short of all these, yet the patients are ready to pay. " (Assistant nurse, 33 years, Malanville)

Perceived Cure For Specific Illnesses: The choice of health care in all the five areas of study was greatly influenced by perceived knowledge of disease causation and the appropriate treatment for the condition. Most notable were those illnesses believed to originate from the supernatural world, leaving the patient at the mercy of these supernatural powers. It is believed that no treatment would cure such an illness, except through the help of God.

"Taking medicines from the hospital is much better than those from the traditional healers. However, there are some diseases that can be healed only by the traditional healers, and others only at the hospital." (Dendi, unmarried adolescent, 16 years, Malanville)

Severity Of Illness: People visit modern health care facilities if the illness remains severe after they have exhausted all other available treatment options. Many people do not go to a hospital for illnesses they do not consider severe.

"When (my son's) sickness started first, we thought it was just a fever attack. I gave him some amulets, then the next day we took him to the Bouanri dispensary but that did not work. We then went to Guere Hospital, still that did not work. We finally came back home and left him in the hands of God. He was no longer speaking, and he was 
not even drinking water. He died one month later." (Peulh, married male, 43 years, Bembereke)

Cost Of Health Service: The main reason why people prefer alternative health care to modern health facilities is the cost. The modern health care facilities are comparatively more expensive and the mode of payment is considered inconvenient. Sometimes an attempt is made to attend hospital but if there is no money to pay for hospital fees, patients end up relying on traditional medicine. Most respondents were of the view that charges for traditional medicine were low and the mode of payment negotiable; patients can pay in kind and sometimes in instalments. Some traditional healers accept payment only when the patient registers full recovery.

Other respondents also argued that they relied on street vendors and markets because they sold products that people could afford. In Malanville, socio-cultural factors, especially religion, play an important role in the choice of health care. Since the larger population is Muslim, they are generally guided by the doctrine of Islam. A health service provider in this area indicated that some women do not like to deliver in hospital because they do not want the service providers to touch their private parts, contrary to Islamic teachings.

\section{FAMILY PLANNING}

\section{Knowledge Of Family Planning In The Community}

Perceptions Regarding Ideal Family Size: Elderly men and women in all the study sites gave vague responses when asked about ideal family size. They strongly believed that family size was a phenomenon only God could determine, often through the onset of menopause.

"It is God who decides the number of children that a woman should have." (Dendi, married woman, 50 years, Malanville)

The younger generations gave more precise responses, with most of them giving figures between six and ten as the ideal number of children a woman should have. This is observed in all the study sites except in Kandi, where smaller figures between two and four are given. Yoruba respondents often referred to the cost of rearing children as an explanation for why couples should limit their children to four or less. These costs include education, food and clothing. Another notable deviation from the general pattern of responses is the apparent preference for boys among the Peulh in Bembereke.

"As for us nowadays, seven children are enough. Others stop at four." (Boo, married woman, 32 years, Kalale)

"We must bear the number of children we can take care of. When we give birth to many children and we cannot take care of them, they become thieves...we poor people must have four children." (Yoruba, married adolescent, 24 years, Kandi) 
"She [a woman] must have nine children, so that there are more boys than girls." (Peulh, married man 39 years, Bembereke)

Knowledge Of Family Planning Methods And Supply Sources: Knowledge of family planning methods in Kalale and Bembereke is very low, and relatively high in Kandi, Malanville and Banikoara. The methods mentioned by the FGD participants in these areas included the IUD, vaginal methods, tubal ligation, the pills, condoms and the injection.

"Sincerely speaking, I have heard of that but I have never seen it. I hear people say that there are pills that allow women to have a break, at least a small break... (laughter from other participants). Yes, I say to have a one or two-year break, which is not a break, but only a small break. I hear people talk about these pills but I have never bought them." (Peulh, married woman, 47 years, Bembereke)

Traditional methods of family planning were widely mentioned in Malanville, where the adult male and female discussants said that rings and amulets are the most used traditional methods. The ability to accurately define family planning and link condom use to AIDS prevention in Banikoara is worth noting.

"There are amulets that you put around your waist or inside your braids. These may help some women but not others." (Dendi, married woman, 30 years, Malanville)

"Even with AIDS around, you can use some of those products and still have sex. But this brings suspicion between husband and wife because the man knows that when he is not around, you can have an affair." (Bariba, married women, 25 years, Banikoara)

FGD discussants were quick to point out that although modern family planning methods are effective, they have adverse effects on the users because they eventually lead to sterility. This is believed to be particularly common among users of the pill and the injection. Other health complications for example, irregular menstrual cycle, weight loss and stomach ache are also observed among these users.

"There is also the Pill, but it is bad for the couple because it often cause sterility." (Yoruba, married woman, 53 years, Kandi)

The discussants were asked the sources of the modern family planning methods that they had mentioned and most of responses indicated that the main source of all the methods was the health facility. It is worth noting that some people obtain modern family planning methods not only from health facilities but also from health service providers and social centre staff who distribute pills outside the facilities. Other non-hospital-based sources of modern family planning (mainly the pill) mentioned by discussants are pharmacies, shops, vendors and black market peddlers who get their supplies from towns in neighbouring Nigeria. 


\section{Perceptions About Use Of Contraceptive Methods}

Demand For Family Planning: There is a strong demand for family planning services in all the study sites. Family planning services are demanded mainly for spacing of childbirths. Many of the respondents argued that spacing gave the mother a break from repeated childbearing and allowed for physical restoration. The child also benefits from the break as he/she gets all the necessary attention from the parents, particularly, concerning health. Respondents also argued that having many children closely spaced is economically strenuous. There was also high demand for the condom among male respondents for prevention against unwanted pregnancies and STDs and HIV/AIDS.

"IIf family planning services existed over here] That would mean that mothers with newly born babies will not fall pregnant that easily. If such services existed over here, we would ask our wives to attend them. They would have really had what they want." (Peulh, married man, 45 years, Bembereke)

Finally, respondents consider family planning as a substitute for sexual abstinence. Demand for family planning is therefore seen as an opportunity for couples to enjoy sex without experiencing unwanted and/or unplanned pregnancies. Respondents often compared this new opportunity with the olden days when couples had to abstain for up to three years in order to maintain well-spaced births and thus ensure good health to mothers and children.

Reasons For Low Utilization Of Family Planning Methods: Despite the apparent demand for family planning services, there is little use of related methods. The community members attribute the minimal use of family planning methods to their lack of knowledge and poor availability of these services.

In all the five study sites, health side effects of family planning methods, whether real or perceived, were the main reason why women in need of family planning did not use it. There was particular concern about the side effects of the pill and the injection, which are believed to cause irregularity in menstruation, stomach cramps, nausea and drastic loss or gain in weight.

"For those small medicines [Pills], when you use them, you will loose weight, sometimes you have stomach ache, it all depends on one's body." (Yoruba, married woman, 34 years, Kandi)

Husband's disapproval is another important factor that explains non-use of family planning methods. This is related to the social stigma that surrounds the use of modern contraceptives. When they learn that their wives are using family planning methods, most husbands get suspicious that their wives may be having sex outside marriage. To avoid this stigma, women often prefer going to local clinics at night to attend family planning services.

"Over here, women prefer the injections. They sneak in at night, take their injections, and go away unnoticed." (Service provider, Malanville) 
Financial constraints also lead to low utilization of family planning methods in the area. The respondents said that many of them could not afford the cost of most of the available methods.

"Some women would like to use those methods but they are financially limited." (Boo, married woman, 34 years, Kalale)

Some respondents said that sexual abstinence was also an important reason for non-use of modern family planning methods. Finally, FGD participants argued that some women do not use family planning methods because they have not attained the number of children they would like to have.

Commonly Used Family Planning Methods: Most respondents suggested that the injection, the pill and the IUD were the most popular methods, although traditional methods were reported as being widely used by the Dendi of Malanville. The male respondents mentioned use of condoms to prevent unwanted pregnancies, STDs and HIV/AIDS. However, it is worth noting that those who use the condom for prevention against STDs and HIV/AIDS do so with sexual partners outside wedlock.

"Yes, I use it for two reasons; if the woman has just delivered, you can have sex with her without any fear. Also, you may meet a girl and you are afraid that she may have AIDS, if you use the condom it will protect you." (Dendi, married man, 50 years, Malanville)

Family Planning Decision-Making: Data from all the five study areas indicate that the husband is the key decision-maker on reproductive issues. This opinion was held across all age groups and sexes. According to female respondents, the possibility of them being key players in decisions about family planning seemed unlikely. Married women attributed male dominance over family planning decision-making and sexual relations to the belief that family planning service providers always require the presence and accord of the husbands.

"It is the husband who decides. If today the husband decides not to get close to the wife at night, how can that woman become pregnant?" (Peulh, married woman, 45 years, Bembereke)

"At the hospital, the health workers always ask you whether you have had the consent of your husband. If you say no, the nurse will send you back to go and bring your husband before she prescribes the product for you." (Boo, married woman, 34 years, Kalale)

The female respondents stated that their insignificant role and subsequent low negotiating power in decisions concerning family planning and sexual relations had led some of them to secretly use family planning methods.

"You can reach an agreement with your husband, but if he refuses, you can go ahead and do it [use contraception] secretly." (Bariba, married woman, 42 years, Banikoara) 
"Some husbands would not let the baby grow up before asking for sex. If she is bothered by the husband, then the wife is forced to go to the hospital without telling the husband." (Yoruba, married woman, 28 years, Kandi)

Respondents justified the supreme role of men in family planning matters and sexual relations by the fact that it was the man that brought the wife and children to the home and was, as a result, in charge of the household in every aspect.

Changes in couples' fertility desires will be dependent on men. Therefore, reaching out to the men should be a central component to any program that aims at influencing change in reproductive behaviour.

Husband/Wife Communication About Family Planning: Discussions between husbands and their wives about family planning are uncommon in all the areas under study. Couples only come close to discussing such an issue when they talk about issues related to the costs of raising children. Respondents said that direct discussion of family planning would lead to social discord, which might result in wife battering and subsequently, divorce.

"They [husband and wife] do not talk about family planning because most of our marriages are arranged and people fear that discussing family planning may cause divorce." (Dendi, married man, 28 years, Malanville)

"We discuss with our wives. Sometimes we talk about how expensive it is to raise children." (Boo, married man, 48 years, Kalale)

It is remarkable that in all the study sites, female interviewees expressed an urgent need for programmes to provide family planning information to husbands to encourage discussion with their wives. The lack of communication between spouses is believed to be a result of lack of information, especially on the part of the husband.

"It would be good if there were an organization with workers who will go from house to house, like the Jehovah Witnesses, to sensitise our husbands so that they also hear." (Yoruba, married woman, 32 years, Kandi)

\section{Contraceptive Use Among The Youth}

Perceptions About Age At First Sex: Although the ideal age at first sex is commonly given as 18 years, most of the respondents were of the view that the current generation of youth starts to engage in sexual activities between the ages of ten and fifteen years.

"It is true that nowadays children start sex very early, that is between ten and fifteen years, and this is valid for both boys and girls. Those who start the earliest are only ten years old. The children start having sex in dark corners and it is the pregnancy that confirms their act." (Yoruba, married woman, 76 years, Kandi) 
Changes in family structure, which increase independence of the youth, are believed to be the cause of early involvement in sexual activities by the youth. The study respondents argued that parents had lost control over the moral education of their children due to the loosening of society's rules regarding marriage. For instance, the respondents argued that in the old days, it was the parents that arranged marriages; in today's 'spoilt world', it is the children themselves who are in control. The respondents felt that roles have been reversed nowadays, with the parents taking instructions from their children like 'ducks following their ducklings'. Early age at first sex was considered to lead to major health risks, including unsafe abortion and death during pregnancy and/or childbirth among adolescents.

"If it were not for the hospital, we would not even have been able to count the number of girls dying when giving birth. Sometimes you wonder how these young girls manage to deliver." (Boo, married woman, 48 years, Kalale)

Perceptions Of Current Use Of Contraceptive Methods Among The Youth: Interviews with adolescent boys and girls indicate that they have good knowledge of contraceptive methods and the respective supply sources, especially in Banikoara. However, there is little indication of use among the youth, especially during their first sexual encounter.

Reasons For Low Use Of Contraceptives By The Youth: Low use of contraceptives by married couples below 24 years of age is attributed mostly to the fact that they have not yet attained their desired family size.

"I have a wife but we are not using any contraceptive method because we do not have children yet." (Peulh, married male adolescent, 23 years, Bembereke)

Many adolescents, both within and outside marriage, also do not use contraceptive methods because of fear of perceived or real health side effects, especially sterility. Some of the fears are based on the perception that some contraceptive products are offered to them after their expiry date.

"Injections often create complications when one wants to resume having children again. The woman finds it difficult to get pregnant and you run all over spending a lot of money." (Yoruba, married adolescent boy, 24 years, Kandi)

Most adolescent respondents contend that they would have used contraceptive methods during their first sexual encounter if they had adequate information on method types and availability.

"It is because I did not know of it. It is only recently that I saw people distributing condoms during a gathering at the hospital." (Dendi, unmarried adolescent boy, 16 years, Malanville)

However, some unmarried adolescent girls say that they know about contraceptive methods but their male sexual partners disapprove of their use. The focus group discussions indicate that the use of contraceptive methods among the youth is closely associated with prostitution and 'sleeping around' in all the five communities under study. The discussants thought that this deters the youth from the use of the methods, because they want to keep a good 
reputation. In Malanville, there is a clear pattern of unmarried adolescent girls relying on traditional contraception, often upon advice from their mothers.

"I am using the 'alfas' [traditional method providers] now that I am not yet married... but my parents do not know. I can tell my mother, but not my father because he will say that I am starting delinquency." (Dendi, unmarried adolescent girl, 15 years, Malanville)

Some adolescent boys and girls attributed non-use of modern contraceptive methods among them to the unfriendly nature of the delivery system. In Kalale for example, adolescent boys suggested that a separate family planning unit be set aside for the youth so that they do not have to go to the hospital where they are often chased away and insulted by the nurses.

The data from IDIs with adolescent boys indicate that the youth are not confident about the effectiveness of some of the modern contraceptive methods. Of particular concern was the condom, which they said was ineffective because of breakage and spillage.

Future Use Of Modern Contraceptives Among The Youth: Most of the youth indicated that they intended to use modern contraceptive methods in the future, after they had attained their desired family size. Others contended that they would only use modern family planning methods if they/their partners had health problems as a result of pregnancy or delivery.

"If it happens that my wife is having health problems for each pregnancy or delivery, then I think that I will use those products." (Peulh, married male adolescent, 23 years, Bembereke)

Interpersonal Communication About Contraception: There is limited communication between parents and their children concerning contraceptive methods. Only a few adolescent girls said that they discussed issues related to contraception with their mothers but not with their fathers. The adolescents attributed the limited communication about contraception to shame and fear of being accused of not wanting children, being labelled as 'spoilt' and disrespectful by their parents.

"Over here, when a child is in a house, he/she will be ashamed to talk about those things with their parents, even if he/she does, the parents will say that it is because that child does not want to have children." (Dendi, unmarried adolescent, 23 years, Malanville)

"If the child is not of a certain age and talk to you about that [contraception], then that is an indication that he/she is a spoiled child. She/he cannot even talk to you about that, may be she/he can talk about that with her mother." (Bariba, married man, 52 years, Banikoara)

However, several adolescent girls and boys indicated that they discussed issues related to contraception with their peers. These include friends, schoolmates and colleagues at work. Young girls who are in apprenticeship (tailoring for instance) mentioned discussions of contraception within their workshops. 
From the analyses above, it is clear that interpersonal communication regarding contraception among the youth is limited to peer groups. Work places (tailoring and mechanic workshops) seem to be conducive for such discussions among youth peers. Misconceptions about contraceptives are widespread, as adolescents are not connected to social networks with proper information about modern contraception. Evidently, the analyses point to more pervasive use of contraceptive methods among the youth, given sufficient information and affordable supplies.

\section{COMMUNITY VALUATION OF HEALTH SERVICES AND PRODUCTS}

\section{Access And Cost Of Health Services And Products}

In all the study sites, respondents did not consider distance to health facilities as a very important factor. People were more concerned about the recovery of the patient rather than the distance to the facilities. There was a notable exception among the Peulh of Bembereke who were concerned about the relatively long distance from Guere hospital, which is larger and better equipped than the local dispensaries.

"Even in that case [Banikoara Hospital], because it is about sickness, it is never far." (Bariba, married woman, 50 years, Banikoara)

"Oh! It is far, but we prefer going there [Guere Hospital]". (Peulh, married adolescent boy, 20 years, Bembereke)

The cost of services offered at health facilities is important to the populations under study. Community members go to far away health facilities if the cost is lower than at the nearer facilities. In Malanville, community members travel as far as neighbouring Nigeria in search for cheaper and affordable health services.

"Sometimes, people don't even think twice, they just cross the border to Lalo/Nigeria to minimize costs." (Dendi, married man, 27 years, Malanville)

The high cost of drugs in health facilities was attributed to theft of drugs by hospital staff, who have set up their own private pharmacies and sell the drugs expensively, then base drug prescriptions on what was available in their pharmacies.

"Are you talking about cost? It is too expensive. When they write a prescription for you and you see the sheet, you will be scared. When you take the prescription to the pharmacy and they tell you the total amount, you just leave it there... You know something, the nurses have their own pharmacies, and they prescribe drugs that you can only find in their private pharmacies." (Boo, married man, 60 years, Kalale) 


\section{Quality Of Services}

The quality of services provided at health facilities was by far the most important concern among the study respondents. The main issues concerning availability and quality of services were lack of drugs and laboratory services, client/provider relationship, lack of skilled staff and staff absenteeism.

"They are much nicer at the Guere Hospital compared to Kandi hospital." (Yoruba, married adolescent girl, 19 years, Kandi)

"In Guere, they take your blood pressure before prescribing medicines to you. While over here [Kandi Hospital] when you have headaches, they just prescribe medicines for you and sometimes it costs up to 500 to 1000 CFA." (Yoruba, married adolescent girl, 21 years, Kandi)

"Some of their staff do not know what the work entails. Some of them do not even have the required degree. When you bring a patient to the hospital, they do not even know which medicine to give him/her. When the person is suffering from headache, they sometimes give him medicines for stomach ache." (Yoruba, married adolescent girl, 24 years, Kandi)

The study respondents thought that Kandi Hospital had the poorest quality of care. While the poor service offered by most of the health facilities is often attributed to a shortage of medical personnel, respondents in Kandi believe that the staff is unskilled and incompetent in the provision of health services.

Rural residents complained that although they constitute the larger share of the population, only small health centres are available to them.

The respondents were of the view that local health facilities do not have enough drugs, largely as a consequence of medical personnel operating parallel businesses and causing deliberate shortages in hospital facilities. Residents of Kalale believe that absenteeism by the hospital staff is also a consequence of running businesses besides their official hospital duties.

"Sometimes, when you ask for drugs at the hospital pharmacy, they tell you that they have run out. When you are about to leave, they tell you that they have it at home." (Bariba, unmarried adolescent boy, 22 years, Banikoara)

"One day, I took my child over there to see the nurse. We suffered a lot. We went to his place, they told us he is in the hospital. Then we went to the hospital and they told us that he was not around. We would like the nurse to available to us." (Boo, married man, 52 years, Kalale)

Most women prefer to deliver in private clinics, where the services are believed to be of good quality and the staff is friendlier compared with public hospitals. Female respondents were of the view that public hospital staff are hostile to women in labour. 
"Before they built the 'Beau Bebe' clinic, I never went to deliver at the hospital. I swear that I bled from one week, and kept asking them what was wrong. The day I was to deliver, the midwife was not around until the head of the baby started coming out. Somebody had to go and look for her. When she came, she did not even put the gloves. This is dangerous." (Yoruba, married adolescent girl, 19 years, Kandi)

Respondents said that the service providers were concerned more about money than the health of their patients. They routinely ask if the patient can afford to pay for treatment before they can attend to him/her. The respondents also complained that they were usually kept waiting too long before being attended to by the medical staff in health facilities. In most cases, the staff sit and chat away, completely unconcerned about the waiting patients.

\section{Suggestions For Improvement By Community Members}

The respondents were asked to suggest ways of improving the health services in their respective areas. Considering the importance accorded to quality of health services, it was not surprising that most of the suggestions made centred around this aspect. To attain good quality services for the large rural populations, the discussants suggested that the supply of drugs and hospital equipment needed be regularized to ensure their sufficiency and lower cost. They argued that they would spend less on transport in search for better services if these services were available in the local health facilities.

They also suggested that only qualified medical personnel should be recruited to deliver medical services in all the health facilities. The discussants in Bembereke were particularly keen on getting staff conversant with Peulh to minimize problems resulting from the language barrier that currently exists.

Female respondents felt that services in maternity units would greatly improve if the service providers changed their attitude and worked towards improving their relationship with the patients.

\section{UTILIZATION OF THE STUDY FINDINGS}

A dissemination seminar was held on November 6-8, 2000 in Parakou, Bénin to share the study results with participants from the Ministry of Health staff in Borgou, staff from the Ministry of Health headquarters in Cotonou, NGOs working in Borgou, PROSAF, and USAID. Workshop participants were divided into workgroups to discuss the implications of the results on existing programmes and what lessons could be learned from the study. The workgroup outcomes are presented in the following section. 


\section{CONCLUSIONS AND RECOMMENDATIONS}

The present study has provided insight into intra-household decision-making regarding health and resource allocation, patterns of health seeking behaviour, and the communities' views of the existing health services in Borgou. The findings highlight important programme implications for the Projet Intégré en Santé Familiale (PROSAF), which is supporting health sector reforms in Benin.

At the household level, adult men make decisions regarding resource allocation in general, and health care expenses in particular. Women are not involved in such decisions. Consequently, the men largely determine patterns of health seeking behaviour in Borgou, including when and where sick household members seek treatment. It has been shown that this is reinforced by the balance of power within the household, which is in favour of men.

The existing patterns of health seeking behaviour in Borgou indicate clearly that patients most often use modern health facilities when the sickness is advanced. Usually communities rely first on traditional healers and self-medication, with modern health services being a last resort. This situation is sustained by prevailing gender roles mentioned earlier, illicit sales of drugs, and existing folk beliefs regarding disease causation and treatment.

Male dominance extends beyond health-seeking behaviour and embraces other aspects of the household's decisions and family planning as well. In Borgou, therefore, reaching men with family planning information is crucial. The Behaviour Change Programme (BCC) addresses unfounded rumours regarding health side effects of contraceptives; however, it must also involve men in order to dissipate husbands' opposition to family planning. Proper training of community-based agents could open up an effective avenue for reaching men through houseto-house visits, as suggested by some female respondents.

PROSAF's Behaviour Change Programme should raise awareness on the need for communities to consider the use of modern health services as soon as sickness occurs. To support such efforts, the BCC program should strengthen capacity at the IEC unit of the Departmental Directorate of Health (DDH). The workshop participants recommended the recruitment of a communication specialist who will be based at the IEC unit of the DDH and who will link up with the BCC program, the local press, and rural radio stations in Borgou. Finally, it was recommended that the communication skills of the staff of the IEC unit of the DDH be upgraded through adequate training.

Community education on the need to seek prompt health treatment must be accompanied by measures aimed at changing behaviour. For instance, increased IEC activities may be fruitless if there are rampant illicit sales of drugs by black marketers and street vendors, thus encouraging local populations to rely heavily on self-medication. While actions must be taken to eradicate the illicit sale of medical drugs, there was general consensus that community education must be broad and should encompass issues such as women's health rights, the financing of the health care system, and men's role in household's production of health. To adequately reach out to Borgou communities on such topics, participants suggested that the BCC programme establish a partnership with NGOs specialized in community education, such as EDUCOM, which has strong experience in working with women's groups in the area. 
The current household-level decision-making on healthcare make women and children vulnerable to ill health. To alleviate this situation, the participants in the dissemination workshop recommended that the existing community-based disease prevention programme of the Ministry of Health be strengthened and expanded. There was a general consensus that the community-based health agents are invisible in most areas. More importantly, the overall quality of health services must be improved to boost the success of the $\mathrm{BCC}$ programme.

Quality of health services was by far the most important concern raised by the study respondents. The main issues regarding quality of service related to shortage of drugs at health facilities, lack of professional qualification and absenteeism of some health staff, and poor client/provider relationships.

According to the study respondents, health personnel who run parallel private drug shops create an artificial shortage of drugs. To ensure the availability of essential drugs at health facilities, staff's skills regarding drug management must be upgraded regularly and the supervision must be reinforced to ensure good practices among health care providers. Even when drugs are available, the study respondents reported that the prices vary from one health centre to another, depending on whether or not the pharmacy staff sell cheaper drugs from their own private shops. Dissemination workshop participants recommended that standard drug prices be posted at all health facilities to inform clients.

Findings presented in this report suggest that staff are often absent from the health centre because they are often busy running lucrative activities parallel to their normal duties. Although this touches upon the thorny issue of staff remuneration and motivation, it also points to the need to strengthen supervision.

Poor client/provider relationships is certainly a reflection of the health staff's poor professional training. In addition to upgrading staff skills in general, it is crucial that health staff be trained on how to relate to clients. Special attention must be paid to adolescents who have indicated that they are often chased away and insulted by health care providers. The workshop participants recommended that these measures should be reinforced by community education regarding their rights and duties when they attend health facilities.

The study respondents reported that they travel long distances and are willing to pay higher costs in the quest of quality health services. While some patients cross the Benin border to seek better care in Nigeria, and others travel to the Guere Hospital reputed for its high quality of services, most pregnant women interviewed in the course of this study indicated that they would prefer to deliver in private clinics instead of being victimized by health staff at the Kandi Hospital. In Kalale, adolescents suggested that a more youth-friendly outlet be built as a separate unit so that they do not have to face the hostile health staff in that area. Improving the quality of health services has the potential of changing current patterns of health-seeking behaviour.

PROSAF is now planning for further dissemination of the study findings to a wider audience of health staff. It is expected that PROSAF's Behaviour Change Communication programme will rely on the present study outcome to design its future strategies. 


\section{REFERENCES}

Coppo, P., L. Pisani and A. Keita (1992): Perceived Morbidity and Health Behaviour in a Dogon Community, Social Science and Medicine, 34 (11): 1227-1235.

Feyisetan, B.J and L. Adeokun (1992): Impact of childcare and disease treatment on infant mortality. In Mortality and Society in Sub-Saharan Africa, (Ed.) E. van de Walle, G. Pison and M. Sala-Diakanda, Oxford: Clarendon Press, 145-159.

Feyisetan, B.J., S. Asa and J.A. Ebigbola (1997): Mothers' management of childhood diseases in Yorubaland: The influence of Cultural beliefs, Health Transition Review, 7 (2): 221-234.

Feyisetan, Bamikale (1988): Understanding the Relationship Between Childcare Practices and Child Mortality: The Need For Ethnographic Approaches in Child Mortality Studies, In Proceedings of the African Population Conference, Liege: International Union for the Scientific Study of Population, 237-254.

Kasl, S. and S. Cobb (1966): Health Behaviour and Illness, Archives of Environmental Health, 12: 246-262.

Mechanic, D. (1978): Illness, In Medical Sociology (Ed.): D. Mechanic: New York: Free Press.

Programme Intégré de Santé Familiale dans le Borgou (1999): Document du Projet.

République du Bénin (1994): Deuxième Recensement Général de la Population et de l'Habitation: La Population du Borgou. Villages et Quartiers de Ville (Cartes de Sous-Préfectures. Ministère du Plan, de la Restructuration Economique et de la Promotion de 1'Emploi, Institut National de la Statistique et de l'Analyse Économique, Fonds des Nations Unies pour la Population.

République du Bénin (1995): Deuxième Recensement Général de la Population et de l’Habitation, Février 1992: Rapport Général. Ministère du Plan, de la Restructuration Economique et de la Promotion de l'Emploi, Institut National de la Statistique et de l'Analyse Économique, Bureau Central du Recensement, Fonds des Nations Unies pour la Population.

République du Bénin (1997): Atlas Monographique des Circonscriptions Administratives du Bénin. Ministère de l'Intérieur, de la Sécurité et de l'Administration Territoriale.

République du Bénin (1997): Enquête Démographique et de Santé: 1996. Ministère du Plan, de la Restructuration Economique et de la Promotion de l'Emploi, Institut National de la Statistique et de l'Analyse Économique, Bureau Central du Recensement, Measure/DHS+.

République du Bénin (1999a): Politique Macroéconomique au Bénin: Progrès, Limites et Perspectives. Ministère du Plan, de la Restructuration Economique et de la 
Promotion de l'Emploi, Institut National de la Statistique et de l'Analyse Économique.

République du Bénin (1999b): Borgou: Analyse Départementale - Analyse Départementale. Résultats de 1'Enquête Démographique et de Santé au Bénin, EDSB-I, 1996. Ministère du Plan, de la Restructuration Economique et de la Promotion de l'Emploi, Institut National de la Statistique et de l'Analyse Économique, Measure/DHS+.

République du Bénin (1999c): Perspectives sur la Planification Familiale et la Santé de la Reproduction au Bénin. Ministère du Plan, de la Restructuration Economique et de la Promotion de 1'Emploi, Institut National de la Statistique et de 1'Analyse Économique, Measure/DHS+.

Sauerborn R., P. Berman and A. Nougtara (1996): Age Bias, But No Gender Bias in the Intra-household Resource Allocation for Health Care in Rural Burkina Faso. Health Transition Review, 6(2): 131-45.

Suchman, E. (1983): Sociology and the Field of Public Health, New York: Russell Sage Foundation.

Ware, N.C., N.A. Christakis and A. Kleinman (1992): In Advancing Health in Developing Countries: The Role of Social Research. (Ed.): L.C. Chen, A. Kleinman and N.C. Ware. 